Archive for

Organic Chemistry

Arkivoc 2020, part vi, 66-72

\title{
A practical synthesis of (3-(phenanthren-9-yl)-4,5-dihydroisoxazol-5-yl)methyl (tert-butoxycarbonyl)-L-alaninate
}

\author{
Francesco Distante, ${ }^{a}$ Simona Collina, ${ }^{b}$ and Paolo Quadrelli*a \\ ${ }^{a}$ Department of Chemistry, University of Pavia, Viale Taramelli 12, 27100 - Pavia, Italy \\ ${ }^{b}$ Department of Drug Sciences, University of Pavia, Viale Taramelli 14, 27100 - Pavia, Italy \\ Email:paolo.quadrelli@unipv.it
}

Received 01-24-2020

Accepted 03-24-2020

Published on line 04-03-2020

\section{Abstract}

Nitrile oxides are highly reactive, but often unstable, compounds that can be used to substitute for other 1,3dipoles in [3+2] cycloaddition reactions. Bioorthogonal chemistry reactions that can occur within living systems without interfering with their native biochemical processes, is an area in which stable nitrile oxides can find useful and valuable applications. The rapid and selective synthesis of a phenanthrene-isoxazolyl derivative containing a protected amino acidic residue, through a facile 1,3-dipolar cycloaddition of a stable phenanthrenenitrile oxide to a $\mathrm{N}$-Boc-protected ( $S$ )-alanine allyl ester as the dipolarophile is described. The synthetic strategy and the fluorescence properties of the single cycloadduct are presented along with the corresponding analytical and spectroscopic data.

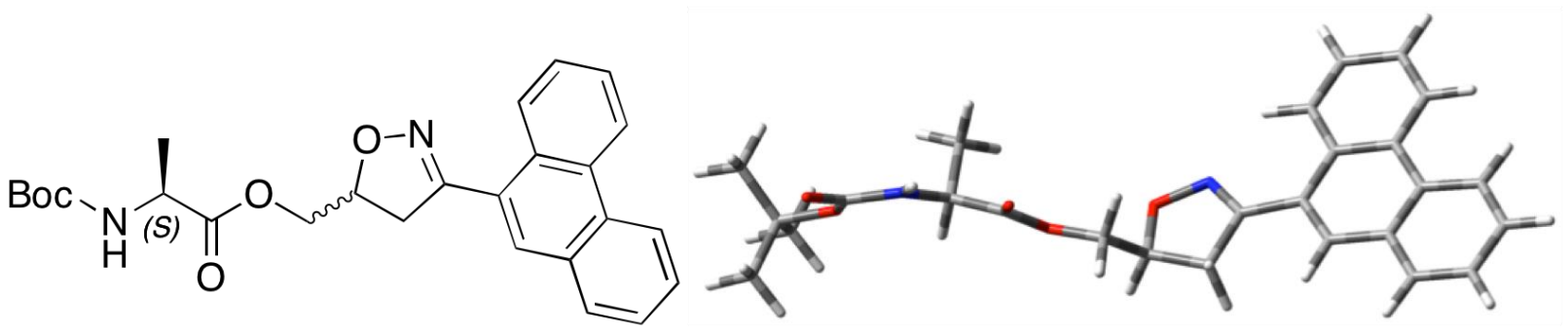

Keywords: Stable nitrile oxides, phenanthrenenitrile oxide, 1,3-dipolar cycloaddition reactions, $L$-alaninate, bioothogonal chemistry, chemical ligation, fluorescent probe 


\section{Introduction}

Nitrile oxides (1) are highly reactive 1,3-dipoles, however, because of their instability, their use in organic syntheses is seriously overlooked other than for the mere preparation of $\mathrm{O}, \mathrm{N}$-containing heterocycles such as isoxazoles (2) and isoxazolines (3) (Scheme 1). At ordinary temperatures, the dimerization rate is extremely high with simple aliphatic and aromatic nitrile oxides, and the corresponding furoxans are normally obtained quantitatively. ${ }^{1}$
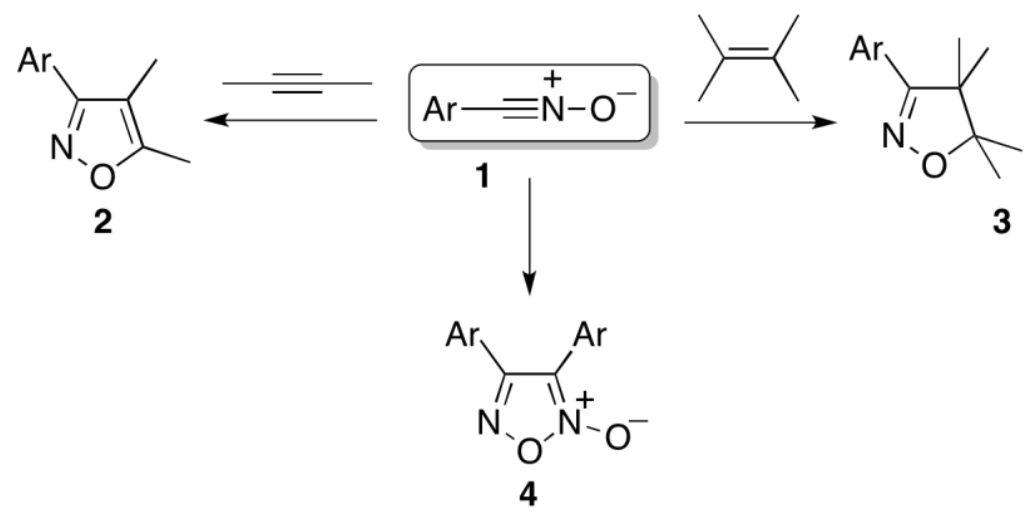

Scheme 1. Synthesis of isoxazoles (2) and isoxazolines (3) from nitrile oxide (1) and dimerization to furoxan (4).

The synthetic simplicity of nitrile oxide precursors, such as oximes, however, starting from the large aldehyde family, has prompted several studies directed towards improving the stability of these 1,3-dipoles. ${ }^{2}$ Luckily, it was found that the dimerization process could be sterically blocked by bulky substituents in the residue attached to the nitrile-oxide moiety ${ }^{1-3}$ Recently, the dimerization process was thoroughly investigated through discrete Fourier transform (DFT) calculations by Houk and co-workers, demonstrating that the ratedetermining step is the formation of the $\mathrm{C}-\mathrm{C}$ bond in a diradical stepwise process. The retardation of dimerization in aromatic nitrile oxides arises from interruption of conjugation between the aromatic substituents and the nitrile oxide group. ${ }^{4}$ The reduced conformation freedom in sterically encumbered aliphatic nitrile oxides presumably increases the activation energy towards the $\mathrm{C}-\mathrm{C}$ bond formation in the same diradical structures.

These findings were somewhat ignored for a long time although they could be of great benefit for several studies where nitrile oxides can nicely replace other 1,3-dipoles in [3+2] cycloaddition reactions. Bioorthogonal chemistry is one of these areas in which stable nitrile oxides can find useful and valuable applications. The expression "bioorthogonal chemistry" refers to any chemical reaction occurring inside of living systems without interfering with native biochemical processes (Figure 1). ${ }^{5}$ 


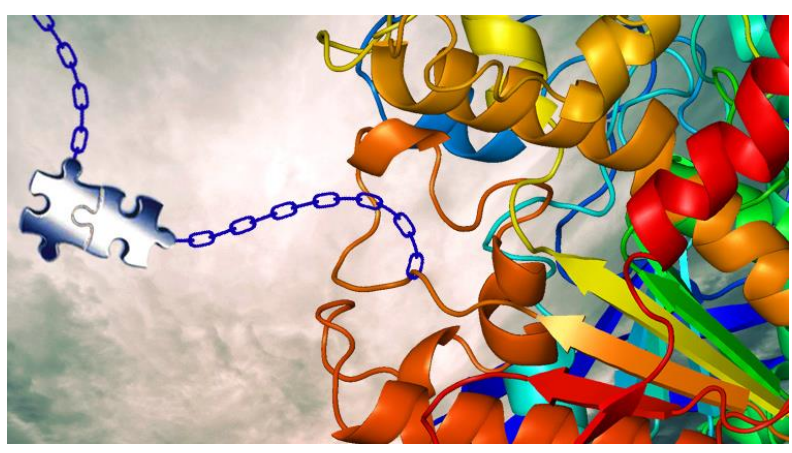

Figure 1. A pictorial concept of bioorthogonal chemistry in living systems.

The chemical nature of bioorthogonal chemistry has enabled the study of glycans, proteins, and lipids in living systems. Chemical reagents must not alter the structure of the substrate dramatically to avoid adversely affecting its bioactivity. Taking into account the chemical data, a reaction is considered to be bioorthogonal if it is selective, biologically and chemically inert, kinetically favorable and biocompatible. ${ }^{6}$ The classical methodologies to perform a reliable chemical ligation are the well-known Staudinger ligation, ${ }^{7}$ the Click $^{2}$ Reactions (such as the Huisgen 1,3-dipolar cycloaddition of azides), ${ }^{8}$ as well as the Diels-Alder (DA) reactions of suitably designed diene systems. ${ }^{9}$

Exploiting the concept of bioorthogonal chemistry, the use of organic molecules with a reduced molecular weight as chemical probes allows a new and interesting chemical design, and represents an outbreaking task in modern organic chemistry research. ${ }^{10}$ Indeed these molecular probes can interact with specific targets in vivo in order to obtain a greater amount of information in complex biological systems. Typically, a general chemical probe contains a fluorescent tag for imaging analysis. ${ }^{11}$

Aiming novel synthetic approaches to Activity-Based Protein Profiling (ABPP), ${ }^{12}$ we describe the rapid and selective synthesis of a phenanthrene-isoxazolyl derivative containing a protected amino acidic residue, based upon a fast and reliable synthesis of a stable phenanthrenenitrile oxide.

\section{Results and Discussion}

The $N$-Boc-protected amino acids are commercially available and can be easily esterified by inserting allylic moieties. This type of unsaturation is prone to become a dipolarophile in 1,3-dipolar cycloaddition reactions. In particular, it is known that mono-substituted alkenes are the most reactive dipolarophiles and, thus, the most suitable compounds for this type of investigations. ${ }^{13}$

A typical esterification reaction was performed through standard DCC/DMAP coupling between the $N$-Bocprotected (S)-Alanine (5) and allylic alcohol (6), affording the desired ester (S)-7 (Scheme 2). The white-solid ester (7) was isolated through column chromatography and obtained in $86 \%$ yield. It was found to be identical to previously synthetized compounds. ${ }^{14,15}$ 


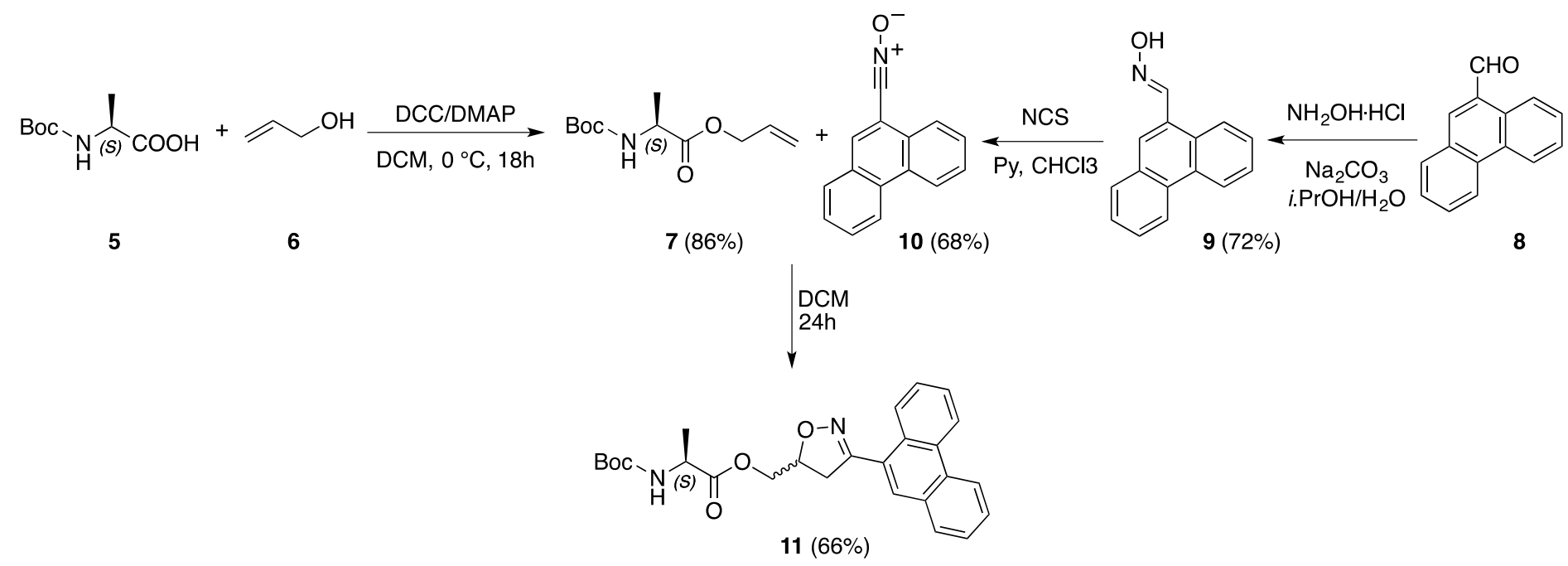

Scheme 2. Synthetic pathways towards the (3-(phenanthren-9-yl)-4,5-dihydroisoxazol-5-yl)methyl (tertbutoxycarbonyl)-L-alaninate (11).

The purified allyl-amino acid (7) was submitted to 1,3-dipolar cycloaddition with a slight excess (1.2 equiv.) of freshly prepared phenanthrenenitrile oxide (10) in dichloromethane (DCM) solution. ${ }^{1}$ The stable nitrile oxide (10) was prepared starting from the phenanthrene 9-carbaldehyde (8) through conversion to the corresponding oxime (9) by standard hydroxylamine addition in hydro-alcoholic solution in the presence of a carbonate, followed by in situ chlorination with NCS and simultaneous dehydrochlorination with pyridine. ${ }^{16}$ Both steps gave the desired compounds in very good yields, and the generation of the nitrile oxide was confirmed by the IR spectroscopy where the $\mathrm{C} \equiv \mathrm{N}-\mathrm{O}$ band was found at $2289 \mathrm{~cm}^{-1}$.

The cycloaddition reaction was conducted at room temperature for $24 \mathrm{~h}$. Chromatographic separation of the worked-up reaction mixture afforded the expected single regioisomer 11, in $66 \%$ yield, as an inseparable mixture of diastereoisomers.

The structure of the cycloadduct $\mathbf{1 1}$ was assigned through the corresponding analytical and spectroscopic data. From the IR spectrum, the presence of the $\mathrm{NH}$ of the Boc-protected amino acidic residue is shown by a band centered at $3352 \mathrm{~cm}^{-1}$; the $\mathrm{C}=0$ groups are shown by the strong and intense bands at 1747 and 1714 $\mathrm{cm}^{-1}$, respectively. The ${ }^{1} \mathrm{H}-\mathrm{NMR}$ spectrum $\left(d_{6}\right.$-DMSO) shows the presence of the phenanthrene ring in the aromatic region with signals ranging from $\delta 7.78 \mathrm{ppm}$ to $8.99 \mathrm{ppm}$. The presence of the newly formed isoxazoline ring is confirmed by the presence of a broad signal at $\delta 5.02 \mathrm{ppm}$ relative to the $\mathrm{CH}-\mathrm{O}$ of the heterocyclic ring, coupled with the exocyclic methylene group, the signals of which are found at 3.54 and $3.86 \mathrm{ppm}$ ( $A B$ system). Another $A B$ system at $\delta 4.36$ and $4.42 \mathrm{ppm}$ corresponds to the isoxazoline methylene. The alanine moiety gave the expected signals of the methyl group at $\delta 1.02 \mathrm{ppm}$ as a doublet coupled with the $\mathrm{CH}$ found at $\delta 4.20 \mathrm{ppm}$ as a typical quartet. The $\mathrm{NH}$ of the amino acid was also found at $\delta 7.39 \mathrm{ppm}$ as a triplet and exchanges with $\mathrm{D}_{2} \mathrm{O}$. Most of the signals are slightly split, denoting the diastereoisomeric mixture. This fact is clearly shown in the ${ }^{13} \mathrm{C}-\mathrm{NMR}$ spectrum. The mixture of diastereoisomers is observed to be in a ratio of approximately $1: 1$, and is due to the undefined chirality of the $C 5$ isoxazoline carbon atom.

The steric effects produced by the phenanthrene moiety of the 1,3-dipole can be seen at work in determining the exclusive regioselectivity of the reaction. Upon investigation of the composition of the crude reaction mixture by NMR techniques, no other compounds were identified in addition to the isolated cycloadduct 11, confirming the specific regiochemical outcome. 
The fluorescence properties given off by the phenanthrene residue to the cycloadduct $\mathbf{1 1}$ were determined by recording a fluorescence spectrum in methanol solvent. The emission maximum is centered at $470 \mathrm{~nm}$ (Figure 2) and is displayed in the cycloadduct only.

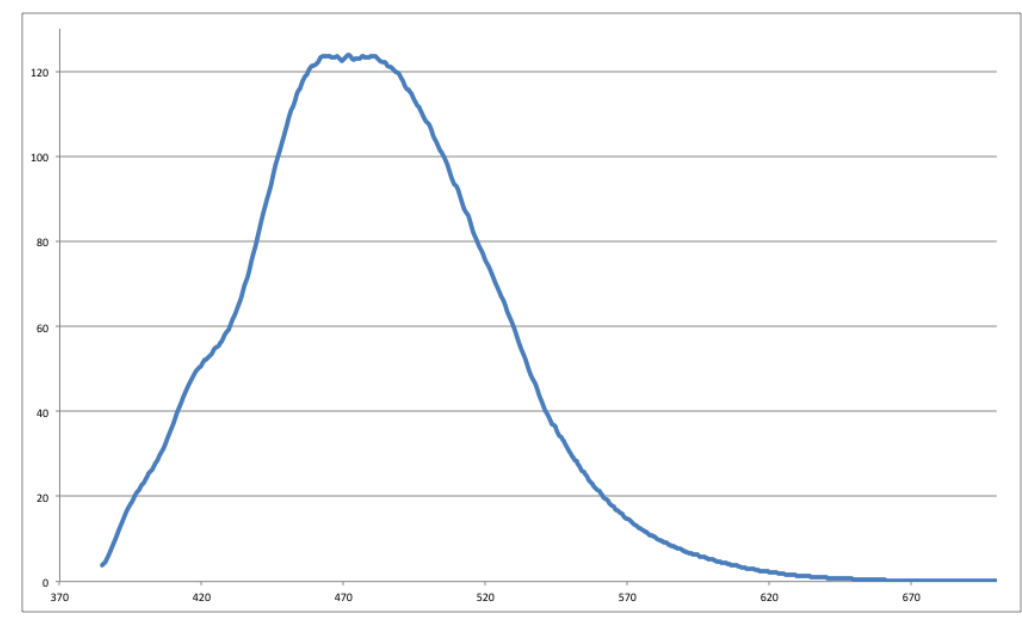

Figure 2. Fluorescence spectrum of the cycloadduct 11 in methanol as solvent.

\section{Conclusions}

In conclusion, the present protocol represents a valuable, reliable, robust and innovative methodology for the synthesis of fluorescence chemical probes for ligation chemistry. The synthesis of the fluorescent cycloadduct of type $\mathbf{1 1}$ can be easily performed by the simple and straightforward preparation of allylic-substituted amino acids, followed by 1,3-dipolar cycloaddition reactions with stable nitrile oxides. Having in hand a variety of aldehydes, the corresponding oximes offer a wide range of nitrile-oxide precursors that, if displaying fluorescence properties, ${ }^{17}$ represent an interesting and promising application for the synthesis of chemical probes for performing ligation studies in living systems without interfering with natural biochemical processes. $^{18}$

\section{Experimental Section}

General. All melting points (m.p.) are uncorrected. Elemental analyses were done on an elemental analyzer available at the department. ${ }^{1} \mathrm{H}(300 \mathrm{MHz})$ and ${ }^{13} \mathrm{C}(75 \mathrm{MHz}) \mathrm{NMR}$ spectra were recorded on a Bruker AVANCE 300 spectrometer (solvents specified). Chemical shifts $(\delta)$ are expressed in ppm from internal tetramethylsilane and coupling constants $(J)$ are in Hertz $(\mathrm{Hz})$. IR spectra (nujol mulls) were recorded on a Perkin Elmer RX-1 spectrophotometer available at the Department; absorptions (v) are in $\mathrm{cm}^{-1}$. The fluorescence spectrum was recorded in methanol solution on a Perkin Elmer LS-55. Column chromatography was run on Kieselgel 60, 70-230 mesh (Merck); eluent cyclohexane/ethyl acetate 9:1 to 1:1).

\section{Synthesis of the phenanthrenenitrile oxide (10)}

Phenanthrene oxime (9) $(0.82 \mathrm{~g}, 3.7 \mathrm{mmol})$ was dissolved in $70 \mathrm{~mL}$ chloroform and $0.4 \mathrm{~mL}$ of freshly distilled pyridine was added. The mixture was then cooled down to $0{ }^{\circ} \mathrm{C}$ and an excess of $\mathrm{N}$-chlorosuccinimide (NCS) 
$(0.57 \mathrm{~g}, 4.3 \mathrm{mmol})$ was added portion-wise under stirring over half an hour. The reaction reached completion in a couple of hours. The organic phase was washed with water and dried over anhydrous $\mathrm{Na}_{2} \mathrm{SO}_{4}$. Evaporation of the solvent left an oily residue that was taken up with diisopropyl ether to crystalize the product. Collection by filtration afforded the nitrile oxide (10) in $68 \%$ yield, $\mathrm{mp} 176-180{ }^{\circ} \mathrm{C}$; IR $v_{\mathrm{C} \equiv \mathrm{N}-\mathrm{O}} 2289 \mathrm{~cm}^{-1} .{ }^{1} \mathrm{H}$ NMR (DMSO$\left.d_{6}\right) \delta 7.80$ (m, $5 \mathrm{H}$, arom.), 8.12 ( $\mathrm{m}, 2 \mathrm{H}$, arom.), 8.92 (m, $2 \mathrm{H}$, arom.). ${ }^{13} \mathrm{C} N M R\left(D M S O-d_{6}\right) \delta 123.3,123.9,124.1$, $125.8,127.8,128.2,128.7,129.4,129.6,129.8,130.1,130.4,145.4,149.2$, 179.7. Anal. Calcd. for $\mathrm{C}_{15} \mathrm{H}_{9} \mathrm{NO}: \mathrm{C}_{\text {, }}$ 82.18; $H, 4.14 ; N, 6.39$. Found: $C, 82.20 ; H, 4.13 ; N, 6.38$.

\section{Synthesis of (3-(phenanthren-9-yl)-4,5-dihydroisoxazol-5-yl)methyl (tert-butoxycarbonyl)-L-alaninate (11).}

To a solution of $204 \mathrm{mg}(0.93 \mathrm{mmol})$ of phenantrene nitrile oxide 10 in $50 \mathrm{~mL}$ of DCM, $300 \mathrm{mg}$ (1.33 mmol) of $\mathrm{N}$-Boc protected alanine allyl ester 7 were added portion-wise under stirring at room temperature and the reaction was conducted overnight. After evaporation of the solvent at reduced pressure, the residue was submitted to column chromatography to isolate the final product $\mathbf{1 1}$ as a yellow solid in $66 \%$ yield, mp 65-70 ${ }^{\circ} \mathrm{C}$ from diisopropyl ether/petrol ether; IR $\mathrm{v}_{\mathrm{NH}} 3352 \mathrm{~cm}^{-1} ; \mathrm{v}_{\mathrm{C}=0} 1746,1694 \mathrm{~cm}^{-1} .{ }^{1} \mathrm{H}$ NMR (DMSO- $\left.d_{6}\right) \delta 1.04(\mathrm{~d}$, $\left.3 \mathrm{H}, J 7 \mathrm{~Hz}, \mathrm{CH}_{3}\right), 3.54,3.86\left(\mathrm{~m}, 1 \mathrm{H}+1 \mathrm{H}, \mathrm{CH}_{2}-\mathrm{O}\right), 4.20\left(\mathrm{q}, 1 \mathrm{H}, J 7 \mathrm{~Hz}, \mathrm{CH}-\mathrm{CH}_{3}\right), 4.36,4.42(\mathrm{dt}, 1 \mathrm{H}+1 \mathrm{H}, J 13,9 \mathrm{~Hz}$, $\left.\mathrm{CH}-\mathrm{CH}_{2}\right), 5.02$ (bs, $\left.1 \mathrm{H}, \mathrm{CH}-\mathrm{O}\right), 7.39(\mathrm{~m}, 1 \mathrm{H}, \mathrm{NH}), 7.78(\mathrm{~m}, 4 \mathrm{H}$, arom.), 8.08 (1H, arom.), 8.16 (s, 1H, arom.), 8.99 (m, 3H, arom.). ${ }^{13} \mathrm{C} \mathrm{NMR}^{*}$ (DMSO- $\left.d_{6}\right) \delta 16.8$ [16.7], 28.1, 49.0, 65.1 [65.0], 77.1 [77.0], 78.1, 122.9, 123.4, 124.8, 127.2, 127.3, 127.4, 128.4, 129.3, 130.0, 130.2, 130.3, 130.4, 155.2, 157.2. Anal. Calcd. for $\mathrm{C}_{26} \mathrm{H}_{28} \mathrm{~N}_{2} \mathrm{O}_{5}$ : C, 69.63; H, 6.29; N, 6.25. Found: C, 69.60; H, 6.30; N, 6.26 .

*Where attributable, the signals of the second diastereoisomer are shown in brackets.

\section{Acknowledgements}

Financial support by the University of Pavia is gratefully acknowledged. COST Action CM1004 "Synthetic Probes for Chemical Proteomics and Elucidation of Biosynthetic Pathways" is also gratefully acknowledged. We also thank "VIPCAT - Value Added Innovative Protocols for Catalytic Transformations" project (CUP: E46D17000110009) for valuable financial support.

\section{Supplementary Material}

${ }^{1} \mathrm{H}$ and ${ }^{13} \mathrm{C}$ spectra are presented in the supplementary material file associated to this manuscript.

\section{References}

1. Grundmann, C.; Dean, J. M. J. Org. Chem. 1965, 30, 2809-2812.

https://doi.org/10.1021/jo01019a074

2. Grundmann, C.; Richter, R. J. Org. Chem. 1967, 32, 2308-2312.

https://doi.org/10.1021/jo01282a047

3. Grundmann, C.; Datta, S. K. J. Org. Chem. 1969, 34, 2016-2018. 
4. Yu, Z.-X.; Caramella, P.; Houk, K. N. J. Am. Chem. Soc. 2003, 125, 15420-15425. https://doi.org/10.1021/ja037325a

5. Prescher, J. A.; Dube, D. H.; Bertozzi, C. R. Nature 2004, 430, 873-877. https://doi.org/10.1038/nature02791

6. Sletten, E. M.; Bertozzi, C. R. Angew. Chem. Int. Ed. 2009, 48, 6974-6998. https://doi.org/10.1002/anie.200900942

7. Saxon, E.; Bertozzi, C. R. Science 2000, 287, 2007-2010. https://doi.org/10.1126/science.287.5460.2007

8. Rostovtsev, V. V.; Green, L. G.; Fokin, V. V.; Sharpless, K. B. Angew. Chem. Int. Ed. 2002, 114, $2596-2599$. https://doi.org/10.1002/1521-3773(20020715)41:14<2596::AID-ANIE2596>3.0.CO;2-4

9. Angell, E. C.; Fringuelli, F.; Guo, M.; Minuti, L.; Taticchi, A.; Wenkert, E. J. Org. Chem. 1988, 53, 4325-4328. https://doi.org/10.1021/j000253a025

10. Frye, S. Nat. Chem. Biol. 2010, 6, 159-161. https://doi.org/10.1038/nchembio.296

11. Verdoes, M.; Florea, B. I.; van der Marel, G. A.; Overkleeft, H. S. Eur. J. Org. Chem. 2009, 3301-3313. https://doi.org/10.1002/ejoc.200900075

12. Willems, L. I.; Verdoes, M.; Florea, B. I.; van der Marel, G. A.; Overkleeft, H. S. ChemBioChem 2010, 11, 1769-1781. https://doi.org/10.1002/cbic.201000280

13. Caramella, P.; Grünanger, P. in 1,3-Dipolar Cycloaddition Chemistry Ed. A. Padwa, Wiley: New York, 1984; Vol. 1, pp 291-392.

14. Memeo, M. G.; Distante, F.; Quadrelli, P. Molbank 2014, M837 https://doi.org/10.3390/M837

15. Hupp, C. D.; Tepe, J. J. J. Org. Chem. 2009, 74, 3406-3413. https://doi.org/10.1021/j0900264p

16. Oliveira, R.; SanMartin, R.; Tellitu, I.; Dominguez, E. Tetrahedron 2002, 58, 3021-3037. https://doi.org/10.1016/S0040-4020(02)00194-1

17. Moggio, Y.; Legnani, L.; Bovio, B.; Memeo, M. G.; Quadrelli, P. Tetrahedron 2012, 68, 1384-1392. https://doi.org/10.1016/j.tet.2011.12.047

18. Minuti, L. F.; Memeo, M. G.; Crespi, S.; Quadrelli, P. Eur. J. Org. Chem. 2016, 821-829. https://doi.org/10.1002/ejoc.201501478 